\title{
Fostering Fluency in an EFL University Classroom: Processes that Lead to it
}

\author{
Miriam Elizabeth Cid Uribe \\ Universidad de Santiago de Chile \\ Faculty of Arts \\ Department of Linguistics and Literature \\ University of Santiago \\ Chile \\ Isadora Reynolds Cavallieri \\ The University of Melbourne \\ School of Languages and Linguistics \\ The University of Melbourne \\ Australia
}

\begin{abstract}
This Action Research investigation describes a two-part intervention aimed at fostering spoken fluency in a chosen teaching setting. They relied on theoretical-practical and authentic material and made use of formfocused instruction and peer reviews. The success rate of the intervention was measured by using qualitative and quantitative data to assess the teaching setting as well as the quality of the materials and methods to be used in both interventions. Quantitative data were analysed to find a correlation between fluency and features of connected speech and to measure improvement in participants' performance. These data were triangulated with native speakers' perception of said performance. The intervention proved effective as participants achieved higher proficiency by accessing features of connected speech. Results from the correlation of both data proved unable to relate features of connected speech and fluency, as shown by native speakers' perception, thus revealing the need for further research in the area.
\end{abstract}

Keywords: fluency - connected speech - perception - teaching setting - action research - qualitative/ quantitative data - assessment

\section{Introduction}

What does it mean to be fluent in a language? The word 'fluent' is a concept that has been reserved for evaluating oral production of non-native speakers, where several conditions must be met to be deemed as fluent (Koponen \& Riggenbach, 2000) while deficiency at any level of language results in judgements of disfluency (Riggenbach, 1991). Fluency is thought to be the utmost attainment for language learners and a fluent speaker is one who has reached the highest level of spoken command of the languages (Brown, 2014; Freed, 2000; Kormos \& Dénes, 2004). Nevertheless, it is unclear how many 'levels' of the language have to be mastered or which these levels are. Overall, it can be affirmed that spoken fluency is a multi-dimensional phenomenon and its definition touches upon phonological, linguistic, paralinguistic, and pragmatic issues amongst the most salient, observable and measurable ones. It is this multi-layered quality of fluency that makes it hard for researchers and educators to study, assess, and/or teach this aspect of oral production. This last statement outlines the first problem with regards to foreign or second language fluency, namely: how can we help students attain the level of command of the language they need to be considered fluent by an interlocutor if language instructors cannot pin down what fluency is?

Another problem that arises, and a reason why it is so relevant to both research and foster fluency, is that it is highly valued not only in academic contexts but also in the 'real-world'. McCarthy $(2009,2010)$ explains how fluency gives you comparative advantage in the labour market being that, for example, an employer is more likely to hire an applicant who shows the best command of the language. In other words, fluency is not only the highest level of achievement, but also a desirable trait in the real world that can result in long-term revenues such as better job opportunities and easier access to higher education in a foreign country. 
Regarding this last point, students who study abroad have been shown to experience acculturative anxiety as a result of perceived lack of fluency (Yeh \& Inose, 2003). Based on this information, we have speculated that it is necessary to inform learners of the advantages of working towards become fluent in a second/foreign language because, we speculate, such awareness can ultimately lead to an increase in motivation.

\section{Literature Review}

The Literature Review touches upon two of the areas that this article deals with: Fluency, definition and research; Fluency, Teaching and Assessment.

\subsection{Defining and researching fluency}

Thus far, early and current literature has divided the phenomenon into two main dimensions based on the definition by Fillmore (1979), namely: higher-order and lower-order fluency. The former considers spoken fluency as a feature of overall language proficiency, the later views it as a purely temporal phenomenon. Higherorder or 'broad' fluency is linked to linguistic and sociolinguistic competence, ranging from segmental accuracy to strategic competence (Anderson-Hsieh, Johnson, \& Koehler, 1992; Ejzenberg, 2000). Considering this, it begs the question of why we should consider this qualitative conception of fluency as separate from proficiency itself. Under the scope of the complexity, accuracy, fluency framework (see Housen, Kuiken, \& Vedder, 2012), fluency is seen as only part of proficiency where the three aforementioned elements interact cyclically in the process of achieving high proficiency in a language. But, above all, fluency is linked to performance and is measured at the level of the acoustic signal, unlike complexity and accuracy which express themselves at all levels of language (Housen et al., 2012; Kormos \& Dénes, 2004). Probably because of this, most of the research regarding fluency has approached it from a temporal perspective. The focus of current fluency studies has been placed on acoustic aspects of the quantity of speech, the speed or rate at which it is produced, and the disruption of this production (Ginther, Dimova, \& Yang, 2010). This has led to the conceptualization of the term 'utterance fluency' which was subdivided in Tavakolil and Skehan (2005) into speed (speed and quantity of speech), breakdown (use of silence in terms of length and number of pauses), and repair fluency (repair strategies used by speakers such as false starts) (see also De Jong, Steinel, Florijn, Schoonen, \& Hulstijn, 2013). This conceptualization of fluency has helped researchers operationalize it for researchers to be able to measure and study it in a more systematic manner (Segalowitz, 2010). Though this approach does not necessarily provide a satisfactory account of what fluency entails or the factors that affect it, it does offer a starting point.

Going back to the issue of fluency as performance, authors such as Segalowitz (2010) have also referred to another dimension of fluency, that is, cognitive fluency. according to him, oral fluency is something speakers possess, statement which is further reinforced in De Jong et al. (2013) who state that it is the ability to plan and execute language. There is not really a 'fluency storage' in the brain, it is closer to a set of skills that allow speakers to reduce inefficiencies and sources of interference. That being said, cognitive fluency is related to the automatization of certain processes in the formulation of spoken language from the preverbal message to overt speech (see De Bot, 1992; Kormos, 2006; Levelt, 1989 for a more complete discussion on the process of speech production). For example, being able to automatize the creation of phonological scores with more efficient movements towards articulatory goals at the level of the articulator, could result in more fluent speech. As will be explained further on, this project hypothesized that the incorporation of features of connected speech into the process of 'prosodification' would make speech articulation faster and more fluent. And, as a would be evident from a review of the studies in this area, faster normally means more fluent.

This leads to the final dimension of phenomenon, that of perceived fluency. It is generally agreed upon that one is only fluent if others deem you as such. That is, fluency is a perception on the part of the listener (Lennon, 2000). But, unfortunately, this means that fluency is a highly subjective concept. As seen in several studies, fluency is both contextual (i.e., influenced by pressures of on-line speech production in the presence of different interlocutors or communicative situations) and inextricably linked to personal preconceptions listeners may have of what it means to be fluent. For example, Fillmore (1979) posited that being fluent entails the ability to speak at length with a minimum of pauses. However, Luoma (2004) explained that what is considered as 'minimum' pausing is a completely subjective construct. Nevertheless, several studies have relied on the use of listener judgements in order to find a link between lower and higher-order fluency (Derwing, Munro, Thomson, \& Rossiter, 2009). That is, researchers have tried to find correlations between measures of utterance fluency and scores given by assessors on the participants' performance in the tasks. 
As explained in Segalowitz (2010), this may lead to a circularity of the argument, where it is difficult to establish which is the dependent variable. In other words, is fluency a property of oral production perceived by listeners or are judgements of listeners what determine what fluency is? Added to this, and returning to the contextual aspect of fluency, authors such as McCarthy (2009) argue that it is not possible to be fully fluent in a monological setting, because fluency is the result of the co-construction of spoken interaction (defined by him as 'confluence'), which reinforces the idea that fluency entails sociolinguistic competence. It is in the interaction with an 'other' that we truly demonstrate our command of the language. Ejzenberg (2000) found that speakers appeared to be more fluent to judges when carrying out dialogic tasks. In spite of this, most studies on fluency rely on monological speech samples to obtain judgements of perceived fluency. However, this does not mean that obtaining judgements using monological samples obtained in laboratory settings is invalid. $\mathrm{Xu}(2010)$ argues that some phenomenon attested in spontaneous speech can be replicated in laboratory conditions, not to mention the fact that tasks such as reading running texts allows for the control of several variables. In this sense, it appears that focusing on the dialogic component of fluency is not as important for the study of utterance fluency but rather, we argue, it is relevant to consider the importance of confluence when fostering spoken fluency.

\subsection{Teaching and Assessing Fluency}

First of all, it should be established that producing spoken language which is fluent in a second or foreign language is known to be more cognitively demanding than in a first language (Kormos, 2006; Segalowitz, 2010). Because of this, and being that fluency is a performance phenomenon, it is unlikely that a learner will become fluent in a language without having achieved a certain level of proceduralisation of speech production. Therefore, we believe it is necessary to foster fluency in EFL and ESL by means of explicit instruction that leads to the acquisition of skills that result in higher levels of competence. That being said, this is not an unproblematic ordeal. The lack of consensus on what fluency entails also makes it difficult to decide which aspects of fluency are to be taught and, later, assessed.

As for the assessment and the teaching of fluency, there are different but intertwined issues surrounding them in the pedagogical field. For the former, there is a tendency to consider spoken fluency as an individual skill when, as a matter of fact, the act of producing spoken language is, most of the times, a dialogic phenomenon. This leads language evaluators to asses it as a monologic skill while, at the same time, rubrics for oral evaluations actually acknowledge this interactive component of language. This can be seen in descriptors for interactive speaking skills in the Common European Framework of Reference (or CEFR) (Council of Europe, 2001), which acknowledge the need for effective interaction with an interlocutor. In the case of the latter, language instructors tend to pay attention to those features of language that they consider more important at the moment of instruction. In addition, it should be noted that spoken performance is taught as an isolated skill, where the student learns and improves those features deemed important by the instructor. Finally, and as a more complex issue, instructors tend to avoid teaching learners about pronunciation explicitly. This has to do with a 'fear' of the theory behind the articulation of the language or a pre-disposition to the futility of teaching the phonology of English (Brown, 2014). Be as it may, this refusal has a detrimental effect on students, who have proven to be more interested in speaking than in any other skill. Taking this into consideration, it would be advisable for teachers to address pronunciation in particular, and oral fluency in general. However, most teaching materials available for this endeavour do not appear to comply with the objectives of their educational context or be, otherwise, too 'oldfashioned' under today's post-method view of language teaching.

Though nowadays the consensus is to recur to whichever methods and materials fit the teachers' style, there are a couple of suggestions that could be followed in order to foster fluency in the classroom. One recommendation put forth by Brown (2014), is to bring literature materials into the class. That is, using authentic materials. This is very much in line with the precepts of more communicative approaches to language learning, notably FormFocused Instruction (FFI). Though it is mainly focused on creating connections between form and meaning in content-based classrooms, the precepts of this approach, namely drawing learners' attention to a particular language forms, lead to the same outcome that we want in terms of fluency, that is "transition from effortful to automatic use of rules" (Saito, 2013, p. 2). It could be suggested, then, that drawing attention to the components of fluency that the instructor wishes to work on as well as incorporating authentic material, could be a good way of approaching the fostering of fluency. 


\section{The Investigation:}

This article reports the results of an investigation carried out at the Pontificia Universidad Católica de Chile and at Universidad de Santiago de Chile, between 2015 - 2016. The general objective of this study was to evaluate the effects of explicit instruction of features of connected speech on measures of utterance fluency and was designed following the procedures of action research. This paradigm for research is a type of disciplined enquiry that is meant to inform future teaching practices under the principles of 'learning by doing' (Ferrance, 2000; O'Brien, 1998). Action research is a 'situated' form of enquiry, meaning that it should be carried out in the researcher's environment and should address an issue that affects a particular community which is not necessarily problematic in other contexts. This is what we could call a 'real-world' problem, and action research is meant to devise a reallife solution to it. To do this, Susman (1983) proposes a five-stage process consisting of: diagnosing, action planning, acting, evaluating, specifying learning, and diagnosing again. This final step of diagnosing is essential, being that if the intervention is not solving the problem, the cycle should start over.

After reviewing the literature on the topic of fluency and evaluating the teaching context where the action research was to take place, it was evident that there was a 'real-life' problem to be addressed. As mentioned above, fluency is a highly-elusive concept, but it is also highly-valued. This led us to believe that it was important to foster fluency in EFL learners both for its pedagogical relevance and because achieving higher oral competence leads to long-term revenues. This particular paradigm is not common in studies of fluency but, as will be seen, it was highly effective in revealing how instructors and learners conceptualize fluency in this setting as well as showing how student participation in the action research cycle can lead to the creation of better and more effective teaching materials and methods.

Though this study followed the postulates of action research, it did rely on a mixed method approach to data collection to assess the effectiveness of the intervention. Both qualitative and quantitative data were collected, so as to diagnose the state of the intervention as well as to validate the results obtained As Rankin (1999) explains, when conducting research, one should attempt to provide multiple perspectives to decide "the problem to be analysed, the intervention to be attempted, and the interpretation to be derived" (p. 117). Only by considering the results obtained from several different instruments can the researcher provide a sound interpretation of the intervention. In order to do this, we collected data using several different instruments. Qualitative data was collected using surveys, these were aimed at first assessing the context of situation, then understanding how fluency was viewed by the instructors and learners in this environment, and finally assessing the quality and effectiveness of the materials used in the intervention. Quantitative data was collected by means of a paragraph of running text meant to elicit the use of features of connected speech and measure whether the intervention had successfully helped students incorporate these into their oral production. Finally, with the aim of triangulating data and ensuring the validity if the tests, we devised a questionnaire that evaluated perceived fluency where experienced instructors judged the speech samples collected to obtain numeric data that could establish connection between connected speech and fluency.

The variables of utterance fluency we chose to study were speech rate, phonation-time ratio, mean length of runs, and pause duration. For the variables of speed fluency, speech rate was chosen because it is considered a measure of 'how fast' the speech of a particular speaker is (Tavakolil \& Skehan, 2005), for it calculates the number of syllables produced per minute (Riggenbach, 1991). Mean length of runs accounts for how 'lengthy' the utterance is between pauses (Tavakolil \& Skehan, 2005). It is said that increases in mean length of runs can be an indication that the speaker has attained higher proceduralisation of knowledge (Towell, 2002). Phonation-time ratio expresses the time spent speaking as a proportion of the total time of an utterance (Towell, Hawkins, \& Bazergui, 1996), and it provides a link between speech and pause phenomena (Vercellotti, 2012). In terms of breakdown fluency, we looked at silent pause duration which are silent periods with no fillers (Cenoz, 2000), but we also focused on the location of pauses. According to Cenoz (2000), pauses placed in locations that do not correspond to syntactic boundaries, or non-juncture pauses, are thought of as 'dysfluent' pauses because they signal disruptions at the level of message formulation. That is, non-juncture pauses are an indicator of a lack of automatization of speech processes.

The intervention was centred on the fostering of fluency by means of developing metacognitive awareness of the components of it, with special emphasis on features of connected speech in English. 
We chose to focus on this aspect of speech for the following reason: fluent oral performance can be related to the different strata of phonetics and phonology, ranging from segmental accuracy to prosody, where suprasegmentals and features of connected speech would be incorporated by L2 speakers ate higher levels of proficiency. Hieke (1985) posits the idea that fluent speech equals connected speech. For example, the phenomenon of linking, or syllable restructuring, can be associated to an "ease-of-effort" principle, motivated by a need to achieve a "maximally fluid" and "minimally complex" articulation which "appears orchestrated to meet speech-dynamic necessities and constraints" (Hieke, 1984, p. 345). In that sense, linking can be considered as a marker for fluent speech, emphasising the relevance of including this feature of connected speech in dynamic oral production.

\subsection{Research question}

How do raising meta cognitive awareness of the components of spoken fluency and providing explicit training of features of connected speech in English improve oral proficiency in terms in learners of English as a second language? How can this improvement be measured temporally and phonologically and be interpreted in terms of perceived fluency? How can the principles of action research inform the creation of materials and implementation of pedagogic methods that can foster the improvement of oral production in terms of fluency and the incorporation of features of connected speech in English?

\subsection{Objectives}

- To investigate the concept of spoken fluency as it manifests itself in second language speakers both in its broad and narrow sense.

- To foster oral fluency in Spanish speakers of English as a second language by developing metacognitive awareness of its components with special emphasis on the teaching of features of connected speech.

- To incorporate the principles of action research into the design of an intervention that can help foster spoken fluency.

- To describe the behaviour of temporal and phonological variables as they contribute to fluency in English.

- To find a connection between these variables and the overall impressions of fluency on the part of a listener.

- To propose a working definition of the concept of spoken fluency in second language speakers that can be used for pedagogical purposes.

- To propose methodological guidelines to be used in the teaching of EFL and ESL with due attention to those features of connected speech that appear to foster oral fluency.

3.3 Hypothesis: spoken fluency in Spanish speakers of English as a second language can be fostered by means of the explicit training of features of connected speech and by rising metacognitive awareness of the components of spoken fluency and this can be done by creating methods and materials based on the principles of action research.

\subsection{Context}

The context chosen for this action research was the English Pedagogy Degree in the Faculty of Humanities at Universidad de Santiago de Chile. Participants in the intervention were students from the second year of the degree, specifically a group of highly-motivated individuals from the 2014 intake. The academics of the faculty also participated in the diagnosing phase by answering our questionnaire. The curriculum of this degree requires students to go through four courses of English phonetics and phonology. These subjects have a high practical component and are organized in a hierarchical manner so that students begin at the segmental level and finish with prosody. However, and something that makes this a particularly interesting context, Universidad de Santiago is well known for having politically active staff and students, who are very committed to issues surrounding access to public education. Because of this, in the year 2015, students from the Faculty of Humanities went on a fivemonth strike to protest against governmental policies. In practical terms, this meant that the students of the English Pedagogy Degree, missed out on the third course of the phonetics and phonology component. Namely, that one dedicated to the teaching and acquisition of features of connected speech. When the study began, participants were enrolled in the fourth course of Phonetics and Phonology, and they manifested that they felt disadvantaged because of a knowledge gap. Therefore, the intervention aimed at helping students who actively voiced their concern about this situation and were willing to participate in workshops outside their regular classroom. Based on the theoretical background, as well as on the nature of the teaching environment and the students' needs, the aspect of fluency taught and developed throughout the intervention was the incorporation of features of connected speech in English, specifically assimilation, elision, linking, and weak forms. 
Other aspects that were dealt with tangentially were: segmental accuracy, correct placement of stress, correct use of intonation patterns, use of compensatory strategies and pauses, and confluence, that is, interacting with an interlocutor. These final aspects were also included in the intervention based on the findings of the instruments described below.

\subsection{Instruments}

\subsubsection{Assessing the context}

The first instrument we designed were two surveys meant to asses the state of the context by delving into the participant's knowledge of the concept of fluency. Another purpose of these questionnaires was to anticipate the needs of the students involved in the study as well as the expectations instructors have about their spoken production in order to design the materials. Added to this, and following the tenets of action research, we intended to make the intervention as situated as possible, which meant we had to address a problem that was pertinent to the community rather than 'creating an issue' based on the intuition of the researchers. One survey was directed at the academics of the faculty, to find out what they prioritized when teaching speaking skills and what they paid attention to when assessing oral production. The survey included three questions related to their perceptions of fluency and how these manifested themselves in the teaching context. Namely, which aspects of spoken language they focused on when assessing spoken performance, which of these they thought was most deficient in their students' speech, and which of these was the most important when grading oral assignments. They were given eight options to choose from, which were based on the aspects of speech at the different strata of language that the review literature mentioned as important for fluency. These were: ability to interact with an interlocutor, choice of register, segmental accuracy, using features of connected speech, correct use of stress and intonation patterns, speed of spoken delivery, correct use of collocations, and grammar and vocabulary.

The second survey was directed at students from the degree and asked participants to describe their own spoken production and what their priorities were as learners. They were asked to rate their fluency, confidence when speaking in class, and confidence when addressing to L1 English speakers using three Likert-scale questions ranked from 1 being the lowest to 7 being the highest. They were then asked to choose which characteristics of spoken language were necessary to manage in order to be fluent and which of these had the greatest impact on their fluency. This was a multiple-choice question and the options were the same as those used for the faculty questionnaire described above. Finally, they were asked to comment on what they thought was the most difficult aspect about speaking in English in the form of an open-ended question.

\subsubsection{Assessing the intervention from the point of view of the participants}

A third survey was designed to evaluate the effectiveness of the intervention based on what participants had experienced and their thoughts on the methods and materials used. The questionnaire included Likert-scale questions, closed questions, and an open-ended question where participants could express their thoughts more freely. The purpose of this instrument was to measure the quality of the materials prepared and the effectiveness of the methods used in the workshops. The Likert-scale questions asked the participants to rank the usefulness of the first and second workshops to improve their fluency, their level of satisfaction with these workshops, and the usefulness of the materials in a scale of 1 to 7 . The closed questions asked about the methods used in the workshops, asking them to choose whether the drilling exercises, peer reviews, use of authentic materials, and focus on weak forms had helped them improve their fluency or not. Finally, they were asked to write any comments or thoughts they had on the workshops.

\subsubsection{Measuring connected speech and utterance fluency}

To measure the effectiveness of the level of command of features of connected speech in English that the participants had, we designed a piece of running text that could elicit the production of linking, elision, assimilation, and weak forms. The paragraph had a total of 435 syllables, and 77 instances of weak forms, 66 linking (52 $\mathrm{C}^{\mathrm{f}}-\mathrm{V}^{\mathrm{i}}$ linking, 6 linking $\left.{ }^{\mathrm{r}}\right], 2$ linking [ $\left.{ }^{\mathrm{w}}\right]$, and 6 linking $\left.{ }^{[\mathrm{j}]}\right), 36$ of assimilation (16 of place and 10 of voice), 43 of elision (17 syllabifications and $16 \mathrm{C}^{\mathrm{f}}$ elision of /t/ or /d/), and 3 instances of elision and assimilation co-occurrence. There were also instances of more 'optional' or 'colloquial' modifications such as $/ \mathrm{v} /$ elision in of (4), h-dropping in weak forms (3), $\mathrm{V}^{\mathrm{i}}$ schwa deletion (3), and progressive assimilation of manner (6). As mentioned in the introduction, we chose to use a running text elicitation method so as to control for extraneous variables thanks to the low cognitive load inherent to this task, and also because our main focus were basic aspects of articulation. This instrument was applied before the intervention as a diagnosis test. 
It was used again after the first workshop and after the second workshop to specify learning and diagnose the effectiveness of the intervention. The text was recorded by a native speaker of SSBE to use it as a guideline for participants and a means by which to compare the results obtained from the participants. The speech samples obtained from the application of this instruments were analysed in search of the production (or lack thereof) of the target features. They were also processed to obtain four measures of utterance fluency so as to establish whether there was a connection between the incorporation of features of connected speech and changes in fluency. For breakdown fluency, we measured the total paused time (or pruned time) and the type of pauses produced, that is, which were placed in juncture and which were placed in non-juncture position. For these variables, we used a pause cut-off of 0.25 [s], following Kormos and Dénes (2004). For speed fluency, we calculated speech rate $[\mathrm{syll} / \mathrm{m}]\left(\mathrm{SR}=\right.$ total $\mathrm{N}^{\circ}$ of syllables / total pruned time $\left.* 60\right)$, phonation-time ratio $(\mathrm{PTR}=$ total pruned time / total time), and mean length of runs (MLR $=$ total syllables / total $\mathrm{N}^{\circ}$ of pauses).

\subsubsection{Measuring perceived fluency}

The final instrument was a questionnaire given to two native speakers. It consisted of four questions, where the first of these was "is this speaker fluent" and the rater could only reply yes or no. The next three were Likert-scale questions ranging from 1 to 7 (one being the lowest, seven the highest), where they were asked to grade how fluent the speaker was, how fast their speech was, and how native-like the speakers sounded. The two judges were shown the different samples obtained from three points in time (before, after the first workshop, and after the second workshop) at random and ask them to answer the questions for each. The main reason why we decided to include this final instrument was to ensure the validity of the interpretation of our results by triangulating data. Also, these numeric results were used as the independent variables when we carried out a simple linear regression models to find correlations between the production of features of connected speech in English, utterance fluency, and perceived fluency.

\section{Intervention}

The intervention was carried out between the second semester of 2015 and January 2016. It consisted of two separate workshops whose focus was fostering fluency, and which took place in the Faculty of Humanities at Universidad de Santiago. Each workshop lasted for four sessions with a two-week break in between.

\subsection{Participants:}

The participants of the intervention were all students from the English Pedagogy degree, attending their second year at that time, between the ages of 19 and 21. At the beginning, 13 students took part of the first workshop and two students worked as a control group. By the end of the second workshop, only four participants had attended all of the eight workshops. Only their speech samples and answers to the questionnaires were considered for the data analysis. These four participants were two females and two males, while the control group consisted of two females, and they were characterized by a great sense of commitment to self-improvement.

\subsection{Materials and methods:}

The first workshop was designed to cover four topics regarding fluency and connected speech. The first was dedicated to the aspects of fluency and linking, then assimilation, then elision, then a review of these three features of connected speech. Other aspects of fluency and connected speech were addressed on-line when and if they happened. The materials prepared for the first intervention were theoretical-practical guides which were divided into four sections: theory and transcription practice, drilling exercises, peer reviewed practice, and group discussion. Theoretical guidelines and the basis for the drilling exercises were inspired by the contents and exercises in the chapters on connected speech in Brown (2014) and Cruttenden (2014). The group discussion was meant to elicit spontaneous speech and give the researcher the chance to provide feedback in terms of those aspects that participants had deemed as most relevant for them in the survey. Each session of the workshop included a feedback section where participants were asked to comment on the material we had used and whether they felt they were working towards improving their oral skills. This final section was included based on what is proposed by the principles of action research, which is collaborative and participatory in nature, and all stakeholders should be part of the decision-making process. Regarding this, feedback from the first session was quite useful and helped fine tune the materials for following three. Participants mentioned we had devoted too much time to theory, and that dividing the session into theory and practice made it harder for them to integrate their learning. Added to this, they also had problems providing feedback to their peers. 
Based on this we modified the study guide for session two using a more FFI approach, where we chose to intersperse theoretical points with drilling and transcription exercises. We added an extra practice section at the end where participants first identified the features of connected speech present in a short passage and then had to practice on their own, with on-line feedback from the researcher carrying out the workshop.

Finally, for the peer reviewed work, we created a questionnaire which helped participants provide more concise feedback. The discussion at the end of the session revealed that the amendments to the materials used were very well-received, so we continued using this format for the final two sessions.

During the specifying learning phase of the intervention, we analysed the speech samples collected from the participants and noticed that there was still work to be done especially with regards to the production of weak forms. In light of this, we decided to carry out a second workshop with a slight change in our approach to the teaching of connected speech and decided to incorporate authentic material. In this occasion, participants worked with an excerpt from Caryl Churchill's 1982 play "Top Girls", which is noted for its use of 'skip-connecting' or overlapping speech (Ivanchenko, 2007). In the except from Act 1 used in the workshop, characters emulate the complex dynamics of real-world spoken discourse by using interruptions and overlaps (Cohen, 1986). We believed that, aside from being used to continue reviewing features of connected speech in context, this made it a suitable piece with which to address features of confluence. For the two first sessions, participants were asked to identify features in the dialogue and read them out loud. They then got immediate feedback from the researcher. In this interaction, we noticed that participants were still struggling with producing weak forms, so we incorporated a chapter from Hewing's (2007) book "English Pronunciation in use Advanced." This piece dealt with weak forms in connected speech in a theoretical-practical manner similar to the one we had used to design study guides for workshop one. A notable aspect of the second workshop was that, by last session, participants were giving each other feedback without relying on the researcher. We believed this to be a great sign of the development of the metacognitive awareness this project was aiming to develop on the participants. The intervention finished with the recording of a final set of speech samples and the survey to evaluate the workshops.

\section{Results}

This following section will report mainly on the results obtained from the surveys collected from the academics and the participants. We will not expand on the numeric data obtained from the speech samples because it is beyond the focus of this article. Also, the small sample size makes it hard to expand our findings to the general population, so the statistical analysis can only be considered pertinent to this context of situation and these particular participants. However, we can mention that the intervention was successful in that the analysis of speech samples showed a great improvement in the incorporation of features of connected speech after the first intervention for all of the features under study, while this improvement was either maintained or slightly reduced after the second intervention. In terms of finding a connection between connected speech and utterance fluency, we were only able to find a significant positive correlation between speech rate and linking $(\rho=0.504$, sig. 0.046). The two other significant correlations were between speech rate and pauses in non-juncture position $(\rho=-$ 0.555 , sig. 0.026) and mean length of runs and pauses in non-juncture position $(\rho=-0.749$, sig. 0.001$)$. however, these final two are not surprising, being that the nature of how SR and MLR are calculated depends on the number and length of pauses in a sample. Regarding the connection between perceived fluency, utterance fluency, and connected speech, the only significant results were found between perceptions of speed and measures of speed fluency. Which, again, is not only logical but expected?

\subsection{What the context revealed about fostering fluency in the EFL classroom}

The survey directed at the initial participants of the first workshop revealed that most of them were not satisfied with their oral performance, with an average score for ratings on spoken fluency of 3.9 (out of 7). It was also evident that participants felt more confident about speaking in the classroom to their teachers (average: 3.8 ) than with native speakers (average: 3.6). The answers given to the multiple-choice questions made it evident that participants believed that fluency was more related to phonological variables than to aspects of grammar and/or pragmatics. Moreover, the interactive components of language were also not thought of as relevant. Table 1 summarises these results. The answers to the open-ended questions reinforced the idea that students in this EFL context are more worried about pronunciation, from segmental to prosodic, than any other aspect. Participants mentioned issues such as use of weak forms, tendency to Spanish-like pronunciation, stress and accent. 
Interestingly enough, the results of the survey carried out on the faculty members differed from what the participants thought was most important in spoken production.

Table 1: Answers to Likert scale questions from the survey carried out on participants before the intervention regarding their oral production

\begin{tabular}{|c|c|c|c|c|c|c|c|c|}
\hline & 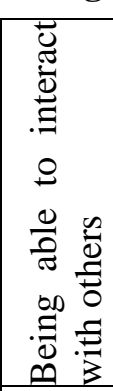 & 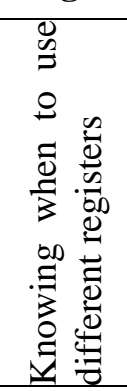 & 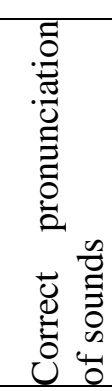 & 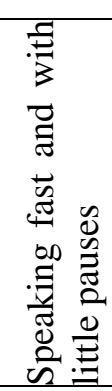 & 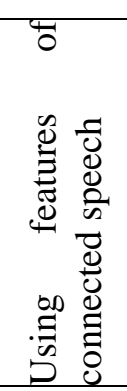 & 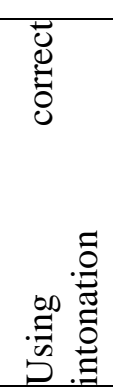 & 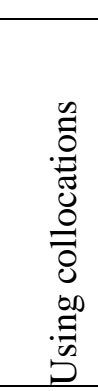 & $\begin{array}{l}\dot{\bar{D}} \\
\bar{\Xi}\end{array}$ \\
\hline $\begin{array}{l}\text { According to your perception, which of } \\
\text { these abilities are necessary to be fluent } \\
\text { in English? }\end{array}$ & $30 \%$ & $30 \%$ & $80 \%$ & $20 \%$ & $60 \%$ & $50 \%$ & $20 \%$ & $0 \%$ \\
\hline $\begin{array}{l}\text { From the above, choose the three } \\
\text { options you find have a greater impact } \\
\text { on fluency. }\end{array}$ & $30 \%$ & $20 \%$ & $70 \%$ & $20 \%$ & $60 \%$ & $60 \%$ & $20 \%$ & $0 \%$ \\
\hline
\end{tabular}

The survey was answered by 9 academics who lecture in the English Pedagogy degree. All of them thought that the ability to interact with an interlocutor was important for oral performance, and the second most relevant features were connected speech, prosody, and the use of collocations ( $78 \%$ for both).

Segmental accuracy came at a close third with $67 \%$ together with choice of register. Speed was not among the most popular choices. When asked what aspect was most deficient in their students' performance, the most popular choice was prosody, followed by segmental accuracy and connected speech. Finally, concerning what they paid most attention to was prosody (56\%) and interaction with interlocutors (44\%). None of the other alternatives was chosen.

What can be extracted when these two sets of results are compared, is that there was a mismatch in this context between what students thought was important for them and what their academics are assessing them on. They did, however, agree on the importance of phonological aspects of speech, but the degree to which they though certain aspects were more relevant varied. While students were more concerned with segments, academics were more concerned with prosody. What can be said about these inferences is that academics worry more about their students being able to communicate with others, i.e., they give importance to interactive features of language, while participants care more about accuracy.

Regarding the questionnaires designed to evaluate the methods and materials used in the intervention, the four participants said the following: first of all, Likert-scale questions revealed that they were more satisfied with the first than the second workshop (5.5 for the first, 6.5 for the second) and thought that was slightly more useful as well (6.3 vs 6.5). Materials used in the second workshop were also more appreciated than those used in the first one (6.5 vs 6.0). This final point was reinforced by the answers to the closed questions. Participants though that using authentic materials helped them improve their fluency more than drilling exercises, they also valued peer work and focusing on weak forms more. In the open-ended question, answered by three of the four participants, they mentioned that the material had been too dense at the beginning of the workshops, that they had appreciated more focus on weak forms, and how the fact that they were able to work in small groups had been positive. Regarding the last point, we believe that it was linked to the fact that it was easier for the researcher to address segmental and prosodic aspects of the participants' production and give feedback on-the-spot. This can also explain why participants preferred peer work over drilling, considering that the former also means that they get to receive on-line feedback about their production.

\section{Conclusions and projections}

This action research was able to account for the importance of fostering fluency in an EFL context based on what was reviewed in the literature and what was revealed from assessing the intervention. 
We found that fluency is highly valued in both academic and non-academic settings, and fostering this skill is beneficial for L2 learners in the long-term. Because of this 'real-world' relevance, we find that it is necessary to provide language instructors and assessors with a pedagogically-oriented definition of the concept of fluency.

As a working definition, we propose that: fluent speech in a second or foreign language means been able to speak at length, with a minimum of unfilled pauses in non-juncture positions, incorporating features of connected speech, producing correct intonation and stress patterns, using formulaic language, and being able to interact with an interlocutor. Language teachers and assessors should also remember that fluency is a performance phenomenon, which means that is can only be fostered by enabling learners to produce overt speech and develop speaking skills that can lead to higher levels of proficiency. But this also means that spoken delivery might not always reflect everything the learner es able to do with the language.

In terms of how to foster fluency, we propose that the main goal is for students to automatize declarative knowledge about the language into procedural knowledge that reflects their proficiency. For this, the first step is to make learners aware of why it is relevant to become more fluent in a language, explicitly addressing the longterm revenues of improving speaking skills. A second step is to design methods and materials that are motivating and consider both the needs of the students and the characteristics of the teaching context. In the environment where our research took place, explicit training of features of connected speech lead lo some improvement in measures of utterance fluency. We do acknowledge that the first materials created, which were based on a more traditional approach of teaching theory explicitly and relying on drilling exercises, was more effective in quantitative terms. Nevertheless, the use of use of authentic material was more motivating for students.

Based on this, we suggest that instructors willing to foster fluency rely on a combination of both drilling and authentic material, but from an FFI approach. Also, we highly recommend that well-designed peer work is encouraged in the classroom, for this allows students to receive immediate feedback on their oral performance as well as developing metacognitive awareness of which aspects of spoken delivery result in more fluent speech.

Possible projections for research into how fluency can be fostered in EFL environments it to take teachers' expectations of how their students should perform in terms of oral skills into account. Researchers can fall into the trap of focusing on aspects of oral production that are interesting to them, while forgetting that our mission is to benefit learners. We should not forget that language learners want to succeed in their teaching context, and, therefore, we should know what is expected of them. Also, instruction should deal explicitly with fluency we should encourage teachers to address spoken production. Another important projection is that this sort of instruction is not to be limited to academic settings. Materials and methods used in this intervention can be adapted to school contexts in order to foster spoken fluency through the features of connected speech in the classroom. If students in teacher-training programs get acquainted with the components of fluency and find ways to address them in their future teaching environments, fluency can be fostered form an early age, leading to students with higher oral proficiency who will have better opportunities in the real-world.

\section{References}

Anderson- Hsieh, J., Johnson, R., \& Koehler, K. (1992). The relationship between native speaker judgments of nonnative pronunciation and deviance in segmentals, prosody, and syllable structure. Language learning, 42(4), 529-555.

Brown, A. (2014). Pronunciation and phonetics: A practical guide for English language teachers. New York, NY: Routledge.

Cenoz, J. (2000). Pauses and hesitation phenomena in second language production. ITL-International Journal of Applied Linguistics, 127(1), 53-69.

Cohen, R. (1986). Spoken discourse in written drama. Essays in Theatre, 4, 85-97.

Council of Europe. (2001). Common European Framework of Reference for Languages: learning, teaching, assessment. Cambridge, U.K.: Press Syndicate of the University of Cambridge.

Cruttenden, A. (2014). Gimson's Pronunciation of English: Routledge.

De Bot, K. (1992). A bilingual production model: Levelt's' speaking'model adapted. Applied Linguistics, 13(1), 1-24.

De Jong, N. H., Steinel, M. P., Florijn, A., Schoonen, R., \& Hulstijn, J. H. (2013). Linguistic skills and speaking fluency in a second language. Applied Psycholinguistics, 34(5), 893-916.

Derwing, T. M., Munro, M. J., Thomson, R. I., \& Rossiter, M. J. (2009). The relationship between L1 fluency and L2 fluency development. Studies in Second Language Acquisition, 31(4), 533-557. 
Ejzenberg, R. (2000). The juggling act of oral fluency: A psycho-sociolinguistic metaphor. In H. Riggenbach (Ed.), Perspectives on fluency (pp. 287-313). Ann Arbor: University of Michigan.

Ferrance, E. (2000). Action research. Providence, RI: LAB, Northeast and Island Regional Education Laboratory at Brown University.

Fillmore, C. J. (1979). On fluency. In Individual differences in language ability and language behavior (pp. 85-101): Elsevier.

Freed, B. (2000). Is fluency, like beauty, in the eyes (and ears) of the beholder? In H. Riggenbach (Ed.), Perspectives on fluency (pp. 243-265). Ann Arbor: University of Michigan.

Ginther, A., Dimova, S., \& Yang, R. (2010). Conceptual and empirical relationships between temporal measures of fluency and oral English proficiency with implications for automated scoring. Language Testing, 27(3), 379399.

Hewings, M. (2007). English Pronunciation in Use Advanced Book with Answers, 5 Audio CDs and CD-ROM: Cambridge University Press.

Hieke, A. E. (1984). Linking as a marker of fluent speech. Language and Speech, 27(4), 343-354.

Hieke, A. E. (1985). A componential approach to oral fluency evaluation. The Modern Language Journal, 69(2), 135142.

Housen, A., Kuiken, F., \& Vedder, I. (2012). Dimensions of L2 performance and proficiency: Complexity, accuracy and fluency in SLA (Vol. 32). Amsterdam: John Benjamins Publishing.

Ivanchenko, A. (2007). An 'interactive'approach to interpreting overlapping dialogue in Caryl Churchill's Top Girls (Act 1). Language and Literature, 16(1), 74-89.

Koponen, M., \& Riggenbach, H. (2000). Overview: Varying perspectives on fluency. In H. Riggenbach (Ed.), Perspectives on fluency (pp. 5-24). Ann Arbor: University of Michigan.

Kormos, J., \& Dénes, M. (2004). Exploring measures and perceptions of fluency in the speech of second language learners. System, 32(2), 145-164.

Kormos, J. (2006). Speech Production and Second Language Acquisition. Mahwah, NJ: Lawrence Erlbaum Associates.

Lennon, P. (2000). The lexical element in spoken second language fluency. In H. Riggenbach (Ed.), Perspectives on fluency (pp. 25-42). Ann Arbor: University of Michigan.

Levelt, W. (1989). Speaking: From intention to articulation. MA: The MIT Press, Cambridge.

Luoma, S. (2004). Assessing speaking. Cambridge: Cambridge University Press.

McCarthy, M. (2009). Rethinking spoken fluency. ELIA, 9, 11-29.

McCarthy, M. (2010). Spoken fluency revisited. English Profile Journal, 1(1), 1-15.

O'Brien, R. (1998). An overview of the methodological approach of action research. In R. Richardson (Ed.), Theory and Practice of Action Research. João Pessoa, Brazil: Universidade Federal da Paraíba.

Rankin, J. (1999). A role for action research in the foreign language classroom. Die Unterrichtspraxis/Teaching German, 107-119.

Riggenbach, H. (1991). Toward an understanding of fluency: A microanalysis of nonnative speaker conversations. Discourse processes, 14(4), 423-441.

Saito, K. (2013). Reexamining effects of form-focused instruction on L2 pronunciation development. Studies in Second Language Acquisition, 35(1), 1-29.

Segalowitz, N. (2010). Cognitive bases of second language fluency. New York, NY: Routledge.

Susman, G. I. (1983). Action research: a sociotechnical systems perspective. Beyond method: Strategies for social research, 95, 113.

Tavakolil, P., \& Skehan, P. (2005). Strategic planning, task structure, and performance testing. In R. Ellis (Ed.), Planning and task performance in a second language (pp. 239-276). Amsterdam: John Benjamins.

Towell, R., Hawkins, R., \& Bazergui, N. (1996). The development of fluency in advanced learners of French. Applied Linguistics, 17(1), 84-119.

Towell, R. (2002). Relative degrees of fluency: A comparative case study of advanced learners of French. IRAL, 4O(2), $117-150$.

Vercellotti, M. L. (2012). Complexity, accuracy, and fluency as properties of language performance: The development of the multiple subsystems over time and in relation to each other. (Doctor of Philosophy), University of Pittsburgh,

Xu, Y. (2010). In defense of lab speech. Journal of Phonetics, 38(3), 329-336.

Yeh, C. J., \& Inose, M. (2003). International students' reported English fluency, social support satisfaction, and social connectedness as predictors of acculturative stress. Counselling Psychology Quarterly, 16(1), 15-28. 